\title{
A IMPORTÂNCIA DA QUALIDADE PARA ATENDIMENTO COM EXCELÊNCIA NO MERCADO IMOBILIÁRIO
}

\author{
Lohana Pereira Garcia ${ }^{1}$ \\ Sérgio Ferreira da Silva ${ }^{2}$ \\ Regina Correa de Moraes ${ }^{3}$ \\ Rogério dos Santos Morais ${ }^{4}$ \\ José Dirnece Paes Tavares ${ }^{5}$
}

Resumo: Esse trabalho propõe identificar a importância da excelência da qualidade no atendimento aos clientes e suas atividades no ambiente imobiliário com objetivo de trazer melhorias para o setor e extrair dessa ação resultados mais robustos e consistentes, devendo acima de tudo o cumprimento dos desafios de novos contratos de negócios. A metodologia aplicada foi pesquisa bibliográfica e entrevista semiestruturada com clientes da empresa estudada. O resultado encontrado nas entrevistas apontou que é possível reduzir o tempo de espera no fechamento de uma venda de imóvel de 80 dias em média para 60 dias, dessa forma estará a empresa satisfazendo e sobretudo criando maior oportunidade de fidelização de seus clientes.

Palavras-chave: Atendimento; Qualidade; Excelência; Melhoria Contínua.

\footnotetext{
${ }^{1}$ Administração/Anhanguera de Jacareí SP, Brasil. E-mail: lohana_garcia@yahoo.com.br.

2 Administração/Anhanguera de Jacareí SP, Brasil. E-mail: sergio.silva@anhanguera.com.

3 Administração/Anhanguera de Jacareí SP, Brasil. E-mail: profareginamoraes@gmail.com.

${ }^{4}$ Administração/ Universidade Braz Cubas, Brasil. E-mail: roger.dos.santos.morais@gmail.com.

5 Administração/Anhanguera de Jacareí SP, Brasil. E-mail: dirluci@uol.com.br.
} 